\title{
Electrochemical Oxidation of the Antiretroviral Drug Nelfinavir on Modified Screen-printed Electrodes
}

\author{
Laura Asturias-Arribas, ${ }^{[a]}$ Mario Raúl Delfino, ${ }^{[b, c]}$ M. Asunción Alonso-Lomillo, ${ }^{[a]}$ Olga Domínguez- \\ Renedo, ${ }^{[a]}$ and M. Julia Arcos-Martínez ${ }^{[a]}$
}

\begin{abstract}
This paper describes the voltammetric study of the electrochemical oxidation of the antiretroviral drug Nelfinavir using a screen-printed sensor modified with carbon nanotubes. The performance of the sensor in the determination of the drug was characterized in terms of precision (RSD $5.05 \%, n=5$ ) and capability of detection $(10.99 \pm 0.87 \mu \mathrm{M}$ for $\alpha=\beta=0.05, n=5)$ under optimized
\end{abstract}

voltammetric conditions of $\mathrm{pH}$, accumulation time and potential, in the calibration range from 10 to $150 \mu \mathrm{M}$ of NFV. In order to check the viability of the device, the determination of the analyte in pharmaceutical and biological samples was carried out and its performance was also validated comparing it with HPLC.

Keywords: Nelfinavir $\cdot$ screen-printed electrode $\cdot$ electrochemical oxidation $\cdot$ carbon nanotubes

\section{Introduction}

Nowadays, Human Immunodeficiency Virus (HIV) is one of the top leading causes of death from infectious diseases in the world. An estimated 34 million people are living with acquired immune deficiency syndrome (HIV/AIDS) worldwide. Additionally, approximately 2.5 million new infections occur annually, from which the $10 \%$ of the infected people are children. The current HIV drugs comprise three important therapeutic families based on the inhibition of different enzymes, namely nucleoside reverse transcriptase inhibitors, non-nucleoside reverse transcriptase inhibitors and protease inhibitors (PI).

Nelfinavir (NFV) is a type of PI of HIV that belongs to the category of antiretroviral PI drugs. The inhibition of the viral protease prevents the cleavage of the gag-pol poly-protein resulting in the production of immature, non-infectious virus. NFV, like other PIs, is generally used in combination with other antiretroviral drugs and is the first nonpeptidic PI available in paediatric formulation.

Its metabolism is mediated by cytochrome P450 (CYP), being the isoenzymes CYP3A4, CYP2C19, CYP2D6 and CYP2C9 primarily involved [1]. After the intake of a normal dosage (between 750 and $1250 \mathrm{mg}$ of NFV), 1$2 \%$ of the dosage is eliminated unaltered through urine [2].

Several reports mainly present the determination of NFV using high performance liquid chromatography with UV [3], UV coupled fluorescence [4] or mass spectrometry [5] detection. Other reported techniques include capillary electrophoresis [6], infrared spectrometry [7], and other chromatographies, such as high performance thin layer chromatography [8], micellar liquid chromatography [9], and UPLC-MS [10]. All these techniques involve expensive instrumentation and pre-treatments like solidphase extraction, increasing the analysis time and the ma- nipulation of the sample, which may lead to errors and contamination.

To the best of our knowledge, no electrochemical method has been described for the determination of NFV, despite having important advantages such as high sensitivity, low detection limit, fast response, relative simplicity and low cost of equipment [11]. Nevertheless, other antiretroviral drugs have already been studied using glassy carbon and boron-doped diamond, modified with a thin-film mercury or without any modification [12].

Screen-printed electrodes (SPEs) are planar devices built with layers of conductive and insulating inks at controlled thickness. Screen-printing technology has made possible the mass-production of low cost disposable electrodes for their use with inexpensive and portable electrochemical instruments. The versatility of SPEs is based on their wide range of possible modifications [13].

Carbon nanotube (CNT) matrices have received considerable attraction in recent years and have been used in chemical and biochemical sensors. This kind of material

[a] L. Asturias-Arribas, M. A. Alonso-Lomillo,

O. Domínguez-Renedo, M. J. Arcos-Martínez

Analytical Chemistry Department, Faculty of Sciences

University of Burgos. Plaza Misael Bañuelos s/n, 09001,

Burgos, Spain

*e-mail: lasturias@ubu.es

[b] M. R. Delfino

Instrumental Analysis Laboratory

Faculty of Natural and Exact Sciences

National University of Northeast. Av. Libertad 5460, 3400,

Corrientes, Argentina

[c] M. R. Delfino

Sensors and Biosensors Laboratory

Faculty of Biochemistry and Biological Sciences

National University of Litoral. Pje. El Pozo s/n. 3000, Santa $\mathrm{Fe}$, Argentina 
exhibits an interesting enhancement in the electrocatalytic activity (increasing the peak current and lowering the overpotential) of the oxidation or reduction of several analytes. These nanomaterials show a $\pi$-conjugative structure with a highly hydrophobic surface, which allows them to interact with some aromatic compounds through $\pi-\pi$ electronic and hydrophobic interactions [14].

The aim of this work is to propose, optimize and validate an electrochemical method for the quantification of $\mathrm{NFV}$ in commercial pharmaceutical preparations and in biological samples, using SPEs modified with multi-wall carbon nanotubes (MWCNT).

\section{Experimental}

\subsection{Reagents and Apparatus}

Home-made screen-printed devices were fabricated using the following commercial inks: carbon ink C2000802P2, gold ink C2041206D2, carbon-platinised ink C2050804D9 and dielectric ink D2071120D1 (Gwent Group, Torfaen, $\mathrm{UK}$ ), silver ink Electrodag 418 and $\mathrm{Ag} / \mathrm{AgCl}$ ink Electrodag 6037 SS (Acheson Colloiden, Scheemda, The Netherlands), and dielectric ink 242-SB (ESL Europe, Agmet Limited, Reading, UK). MWCNTs were purchased from DropSens S.L. (Oviedo, Spain) and their dispersions were prepared in dimethylformamide (DMF, Panreac, Barcelona, Spain). Stock standard solutions of NFV (Sigma-Aldrich, Steinhein, Germany) were prepared by dissolving the adequate amount of the drug in ethanol (VWR Prolabo, Fontenay-sous-Bois, France). A solution containing $100 \mathrm{mM} \mathrm{KCl}$ (Sigma-Aldrich, Steinheim, Germany) and $50 \mathrm{mM}$ phosphate buffer $\left(\mathrm{NaH}_{2} \mathrm{PO}_{4} \cdot 2 \mathrm{H}_{2} \mathrm{O}\right.$, Merck, Darmstadt, Germany) in Milli-Q water was used as supporting electrolyte and adjusted to the desired $\mathrm{pH}$ value with $1 \mathrm{M}$ $\mathrm{NaOH}$ (J.T. Baker, Deventer, The Netherlands) and $1 \mathrm{M}$ $\mathrm{HCl}$ (VWR Prolabo, Fontenay sous Boris, France) solutions. A $5.7 \mathrm{mM} \mathrm{K} \mathrm{K}_{3} \mathrm{Fe}(\mathrm{CN})_{6}$ (Merck, Darmstadt, Germany) solution in $100 \mathrm{mM} \mathrm{KNO}_{3}$ (Merck, Darmstadt, Germany) was used for the electrochemical activation of gold electrodes.

The mobile phase for liquid chromatography assays was prepared using acetonitrile, methanol (Merck, Darmstadt, Germany) and a $0.05 \%$ w/v solution of dimethylamine (Merck, Darmstadt, Germany) in $10 \mathrm{mM}$ ammonium acetate (PRS Panreac, Barcelona, Spain), in a $45: 20: 35$ proportion. The $\mathrm{pH}$ was adjusted to 6.5 with $1 \mathrm{M}$ acetic acid (VWR Prolabo, Fontenay sous Boris, France) solution.

Viracept ${ }^{\circledast}$ Nelfinavir $250 \mathrm{mg}$ tablets were kindly provided by Roche Ltd.

A DEK 248 screen printer (DEK, Weymouth, UK) was used for the fabrication of the screen-printed transducers. Electrochemical measurements were made with a $\mu$ Autolab Type II potentiostat/galvanostat with GPES software (Eco Chemie, Utrecht, The Netherlands). The $\mathrm{pH}$ of the solutions was measured with a Crison Model $2002 \mathrm{pH}$ meter (Barcelona, Spain). A HPLC Perkin Elmer Model
Flexar with UV-Vis detector and binary pump, controlled by Chromera software (Waltham, Massachusetts, USA), was used for the chromatographic determination of the dosage of NFV in pharmaceutical tablets.

\subsection{SPEs Fabrication}

SPEs were manufactured in our laboratory by sequential deposition of different commercial inks on polymeric sheets, followed by their curing process [15].

Electrodes of different nature were fabricated using different kinds of inks. In this way, two types of SPEs were built. Firstly, SPEs based on a 3-electrode configuration (a $12.6 \mathrm{~mm}^{2}$ working, a $\mathrm{Ag} / \mathrm{AgCl}$ reference and a carbon counter electrodes) have been manufactured according to previously described procedures using gold, carbon and platinised carbon inks to define the working electrode [16]. In this way, three different devices were obtained: screen-printed gold electrodes (SPAuEs), screen-printed platinised carbon electrodes $\left(\mathrm{SPC}_{\mathrm{Pt}} \mathrm{Es}\right)$ and screen-printed carbon electrodes (SPCEs).

Secondly, a carbon working electrode $\left(144 \mathrm{~mm}^{2}\right)$ was printed in the polymeric sheets to be used as part of a three electrode configuration with commercial $\mathrm{Ag} / \mathrm{AgCl}$ reference and conventional platinum electrodes, which were used for the chronocoulometric measurements.

Due to the nature of the gold ink, SPAuEs were mechanically and electrochemically activated [16a]. Initially, the working electrode was sanded with thin grain sandpaper to obtain a shiny surface. Then, the working electrode surface was activated by recording 8 cycle voltammograms between +800 and $-800 \mathrm{mV}$ vs. $\mathrm{Ag} / \mathrm{AgCl} \mathrm{SPE}$, scan rate $100 \mathrm{mV} \mathrm{s}^{-1}$, in $100 \mu \mathrm{L}$ of a $5.7 \mathrm{mM}$ ferricyanide solution in $100 \mathrm{mM} \mathrm{KNO}_{3}$.

$\mathrm{SPC}_{\mathrm{Pt}}$ Es and SPCEs were used without any pretreatment.

\subsection{Modification of SPCEs}

In order to modify the working surface of the SPCEs with MWCNTs, $5 \mu \mathrm{L}$ of a $3 \mathrm{mg} \mathrm{mL}^{-1}$ dispersion of MWCNTs in DMF were dropped on the working electrode and the solvent was left to evaporate overnight at room temperature [13b].

\subsection{Electrochemical Measurements}

Square-wave voltammetric (SWV) measurements were carried out in a cell containing $5 \mathrm{~mL}$ of the supporting electrolyte solution of the selected $\mathrm{pH}$. Experimental parameters of frequency $(25 \mathrm{~Hz})$, step potential $(12 \mathrm{mV})$ and amplitude $(25 \mathrm{mV})$ were fixed, leaving for optimization the accumulation step. Hence, before recording the anodic scan from +500 to $+1500 \mathrm{mV}$ (vs. Ag/AgCl SPE), the solution was stirred for $50 \mathrm{~s}$, applying a deposition potential of $200 \mathrm{mV}$.

Chronoamperometric and chronocoulometric measurements were carried out under constant stirring in a cell 
containing $5 \mathrm{~mL}$ of $10 \mu \mathrm{M}$ of NFV in supporting electrolyte $\mathrm{pH}$ 2. A potential of $+950 \mathrm{mV}$ (vs. $\mathrm{Ag} / \mathrm{AgCl} \mathrm{SPE}$ ) was applied during an hour.

All measurements were performed at room temperature.

\subsection{Chromatographic Measurements}

The chromatographic system consisted on a UV-detector fixed at $225 \mathrm{~nm}$; isocratic mode at a flow rate of $1.0 \mathrm{mLmin}^{-1}$; a $\mathrm{C} 18$ column of dimensions $4.6 \mathrm{~mm} \times$ $15 \mathrm{~cm} \times 5 \mu \mathrm{m}$ and an injection volume of $20 \mu \mathrm{L}$.

\section{Results and Discussion}

Previous experiments carried out in our lab showed that NFV (Fig. 1) is an electrochemically active molecule, giving an oxidation voltammetric peak around $+1000 \mathrm{mV}$ in acidic media.

Since the nature of the screen-printed working electrode influences the electrochemical behavior of NFV; SPAuEs, SPC $_{\mathrm{Pt}}$ Es, SPCEs and MWCNT-SPCEs were used for the voltammetric determination of NFV. Square-wave voltammograms of a $150 \mu \mathrm{M}$ NFV solution in supporting electrolyte $\mathrm{pH} 2$ were recorded using the different SPEs. SPAuEs presented a peak at $+1000 \mathrm{mV}$ (vs. $\mathrm{Ag} / \mathrm{AgCl}$ SPE) caused by the oxidation of the gold surface, close to the oxidation peak of NFV, which led to an irreproducible working surface. Thus, SPAuEs were not suitable for this analysis.

On the other hand, the current of the oxidation peak of NFV obtained with SPCEs, $\mathrm{SPC}_{\mathrm{Pt}}$ Es and MWCNTsSPCEs were 3.6; 6.2 and $70.0 \mu \mathrm{A}$, respectively (Fig. 2). So the chosen electrodes for the study of NFV were MWCNT-SPCEs.

\subsection{Optimization of the Experimental Variables}

The electrochemical response of NFV on the MWCNTSPCEs is a function of the $\mathrm{pH}$ of the solution and the ac-<smiles>Cc1c(O)cccc1C(=O)N[C@H](CSc1ccccc1)[C@H](O)CN1C[C@H]2CCCC[C@H]2C[C@H]1C(=O)NC(C)(C)C</smiles>

Fig. 1. Molecular structure of nelfinavir mesylate.

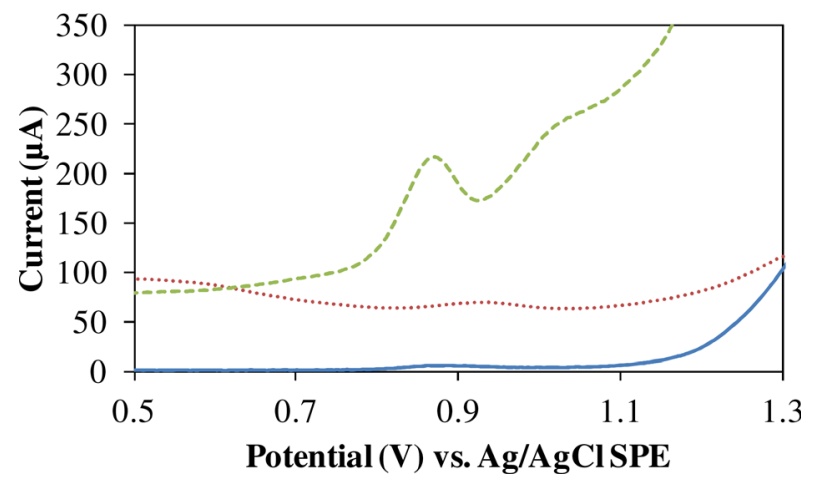

Fig. 2. Voltammetric oxidation at the optimum conditions (accumulation at $200 \mathrm{mV}$ during $50 \mathrm{~s}$ ) of a $150 \mathrm{mM}$ NFV solution in supporting electrolyte $\mathrm{pH} 2$ using SPCEs (full line), $\mathrm{SPC}_{\mathrm{Pt}} \mathrm{Es}$ (dotted line) and MWCNT-SPCEs (dashed line).

cumulation process. In order to obtain a good analytical signal that could allow the quantification of NFV, these variables were optimized by means of an experimental design. The data analysis was processed with STATGRAPHICS PLUS [17], software package for the experimental design process [18].

In this way, a $2^{3}$ central composite design, which enabled us to analyze five levels of each of the three influential variables $(\mathrm{pH}$ of the medium, accumulation potential (vs. $\mathrm{Ag} / \mathrm{AgCl} \mathrm{SPE})\left(\mathrm{E}_{\text {acc }}\right)$ and accumulation time $\left(\mathrm{t}_{\mathrm{acc}}\right)$ ), was carried out. Two levels were selected, high and low, for each factor. Then, 17 experiments were performed corresponding to all possible combinations and three replicates of the central point were necessary to estimate the residual value.

The central point (0) and the values of high $(+)$ and low (-) levels for each factor were the following:

$$
\begin{array}{llc}
\mathrm{E}_{\text {acc }}(+)=300 \mathrm{mV} & \mathrm{t}_{\mathrm{acc}}(+)=90 \mathrm{~s} & \mathrm{pH}(+)=4 \\
\mathrm{E}_{\mathrm{acc}}(-)=100 \mathrm{mV} & \mathrm{t}_{\mathrm{acc}}(-)=30 \mathrm{~s} & \mathrm{pH}(-)=2 \\
\mathrm{E}_{\mathrm{acc}}(0)=200 \mathrm{mV} & \mathrm{t}_{\mathrm{acc}}(0)=60 \mathrm{~s} & \mathrm{pH}(0)=3
\end{array}
$$

The optimum values obtained from the experimental design were $200 \mathrm{mV}$ for the accumulation potential, $50 \mathrm{~s}$ for the accumulation time and a $\mathrm{pH}$ value of 2 .

\subsection{Precision and Capability of Detection}

The performance of the developed MWCNT-SPCE was checked in terms of precision and capability of detection. Different calibration curves were recorded in the calibration range from 10 to $150 \mu \mathrm{M}$ of NFV under the optimal conditions. The incorrect adjustments were avoided using the program PROGRESS, which evaluated the presence of anomalous points using a least median squares regression (LMS) [19]. Then, ordinary least squares (OLS) regressions were built using the remained data.

The slopes of these regression curves were used to estimate the reproducibility of the sensor in terms of relative 


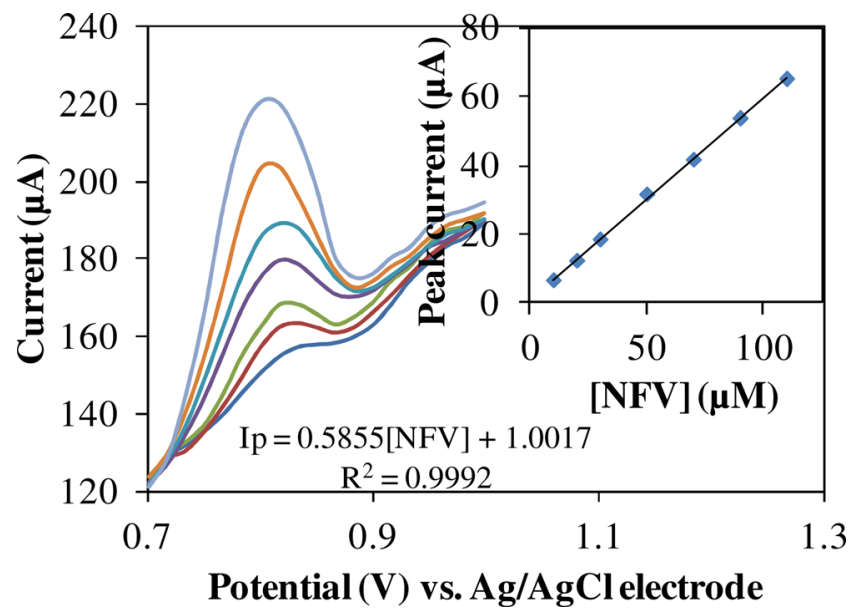

Fig. 3. Square-wave voltamogramms obtained for 10, 20, 30, 50, 70,90 and $110 \mu \mathrm{M}$ of NFV at the optimal conditions of $\mathrm{pH} 2$, $E_{\text {acc }}: 200 \mathrm{mV}$ and $\mathrm{t}_{\mathrm{acc}}: 50 \mathrm{~s}$. Insert, calibration curve for the determination of NFV by SWV with MWCNT-SPEs.

standard deviation (RSD). So, the calibration curves recorded using different MWCNT-SPCEs have given a reproducibility of $5.05 \%(n=5)$ for a linear range of 10 $110 \mu \mathrm{M}$ of NFV (Fig. 3). The repeatability was carried out in the same way as for the reproducibility but using the same MWCNT-SPCE. However, it was observed that it was not possible to perform more than one calibration curve with the same electrode, possibly due to the adsorption of the oxidized product of the NFV in the surface of the working electrode. This fact is not really significant due to the disposable nature of the sensor and its good reproducibility.

The capability of detection was calculated for a probability of false positive $(\alpha)$ and false negative $(\beta)$ [20], obtaining a value of $10.99 \pm 0.87 \mu \mathrm{M}(n=5)$ for $\alpha=\beta=0.05$.

\subsection{Mechanism of Oxidation}

In order to elucidate the electrochemical oxidation mechanism of NFV, the comparison of the voltammetric signal of NFV with the signals of some phenolic groups described in bibliography was carried out. This comparative study showed that the voltammetric behavior of NFV was similar to the one observed for the phenol [21]. As it is shown in Fig. 4, the phenol oxidation peak is observed around $+860 \mathrm{mV}$ in the first scan, and two reduction peaks appeared at backwards direction. In the second scan, two additional oxidation peaks appeared, while the initial oxidation peak decreased. Taking this into account, the phenol group could be thought to be the one responsible for the voltammetric oxidation signal of the molecule.

According to the bibliography, the oxidation of the phenol group requires one electron and one proton [21a]. Bearing this in mind, a chronocoulometry was performed in presence and absence of NFV in order to determine the number of electrons that take part in the oxidation

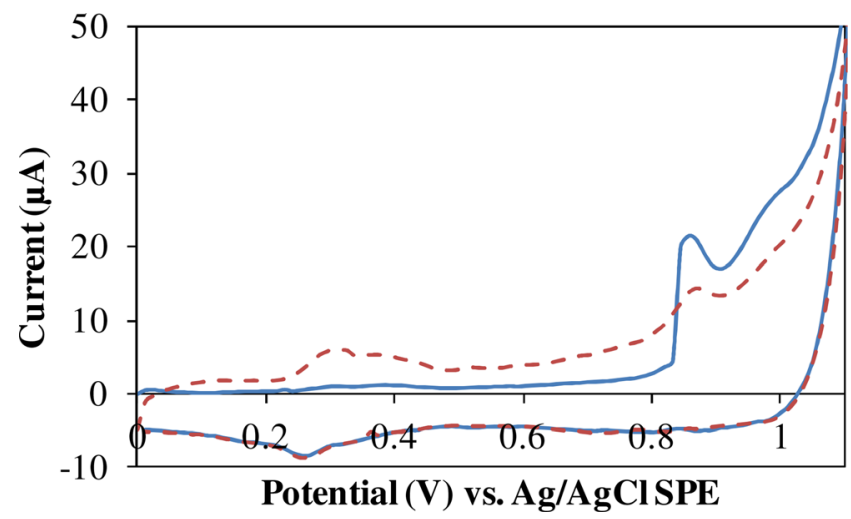

Fig. 4. Two consecutive cyclic voltammograms ( $1^{\text {st }}$ (full line) and $2^{\text {nd }}$ (dashed line) scans) of the voltammetric behavior of a solution containing $50 \mu \mathrm{M}$ of $\mathrm{NLV}$ in supporting electrolyte $\mathrm{pH} 2$ using MWCNT-SPCEs, scan rate $50 \mathrm{mV} \mathrm{s}^{-1}$.

signal of the analyte. Taking the value of charge after one hour and using Faraday's law, the number of transferred electrons reached was one.

The estimation of the number of transferred electrons was also carried out using Tafel plot [22]. After recording the voltammetric cycle of a $5 \mathrm{mM}$ solution of NFV, the values of $(\log \mathrm{I})$ vs. applied potential were represented and the value of $n(1-\alpha)$, obtained from the anodic branch of this graphic, was found to be 0.65 . As this system is irreversible, $0<\alpha<0.5$, the number of electrons (n) will be around 1.

The number of protons that are required in the reaction was studied by the variation of the peak potential with the $\mathrm{pH}$. It is reported that the aqueous solubility of nelfinavir is strongly dependent on $\mathrm{pH}$, showing a sharp decline in solubility at $\mathrm{pH}$ values above 4.5 [23]. For that reason, this study was limited by the fact that the $\mathrm{pH}$ interval, in which the NFV was soluble and its peak was visible, was narrow, between $\mathrm{pH} 2$ and 4.5. An initial scanning at acidic, neutral and basic $\mathrm{pH}$ values was made to have a first idea where the signal of NFV could be higher. Additionally, the peak potential difference between pH 2 and 4.5 was $25 \mathrm{mV}$ when using MWCNTSPEs and $100 \mathrm{mV}$ when using $\mathrm{SPC}_{\mathrm{Pt}}$ Es, so $\mathrm{SPC}_{\mathrm{Pt}}$ Es were chosen to be used for this study. In this way, SWV measurements were carried out with $\mathrm{SPC}_{\mathrm{Pt}}$ Es at different $\mathrm{pH}$ values, the peak potential versus the $\mathrm{pH}$ value was represented and the expression of the Nernst equation was used [22]. As a result, one proton was needed in the process.

Taking into account the experiments and the information obtained from the bibliography, the suggested mechanism for the electrochemical oxidation of NFV is represented in Fig. 5. The oxidation of the phenol group of NFV produces para- and ortho-quinones, which can be reduced into its respective hydroquinones. This behavior can be observed and explained with the representation in Fig. 4, where in the first scan just the oxidation of the phenol group is shown, but in the backwards branch two 


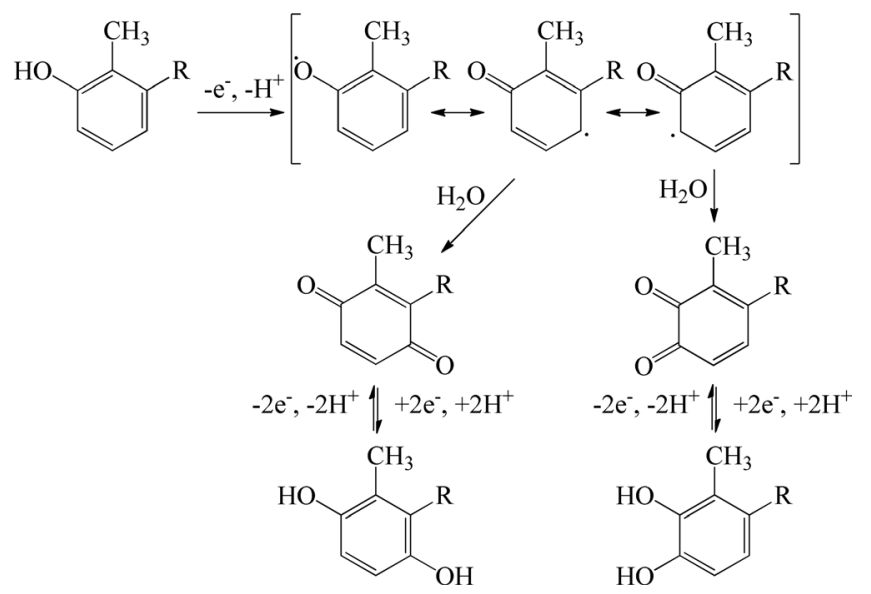

Fig. 5. Suggested mechanism of the electrochemical oxidation of NFV.

reduction peaks are observed due to the reduction of the quinones. In the second scan these products are oxidized and that is why two oxidation peaks appeared, which in the first scan did not.

\subsection{Application in Pharmaceutical Drugs and Biological Samples}

Both pharmaceutical and biological samples were measured by the standard addition methodology using MWCNT-SPCEs.

Viracept ${ }^{\circledast}$ is a drug widely used in highly active antiretroviral therapy (HAART) with a theoretic composition of $250 \mathrm{mg}$ of NFV per tablet. 15 tablets of this drug were weighted and the average weight was calculated. Then, all these tablets were pulverized in a mortar and the sample solutions were prepared by dissolving the necessary amount in ethanol to obtain an approximate concentration of $5 \mathrm{mM}$.

In order to perform the voltammetric measurements, a volume of $50 \mu \mathrm{L}$ of the sample solution of the pharmaceutical drug was dissolved in $5 \mathrm{~mL}$ of supporting electrolyte $\mathrm{pH} 2$, and consecutive additions of a solution of NFV were performed. The amount of NFV found was $249.3 \pm$ $1.9 \mathrm{mg}$ per tablet $(n=5, \alpha=0.05)$. This quantity is in accordance with the values labeled by the manufacturer, and agrees with tolerance levels of the Pharmacopoeias ( $\pm 10 \%$ of the declared dosage) [24].
Table 1. Results of comparison of SWV with MWCNT-SPCEs and HPLC-UV methods. Values in parenthesis correspond to those tabulated for $\mathrm{p}=0.05$.

\begin{tabular}{lll}
\hline Parameter & HPLC-UV & MWCNT-SPE \\
\hline$X \pm S$ & $249.72 \pm 4.29$ & $250.49 \pm 3.59$ \\
$n$ & 5 & 5 \\
$R S D \%$ & 1.72 & 1.43 \\
$S^{2}$ & 18.38 & 12.91 \\
$F$ test & $0.3703(6.3882)$ & \\
t test & $0.7659(2.3060)$ & \\
\hline
\end{tabular}

In order to test the reliability of the proposed method, the determination of NFV in the pharmaceutical tablets was also performed by HPLC [24]. The results obtained with SWV and HPLC were compared using the F test for precision and the $\mathrm{t}$ test for means (Table 1). Statistically, there are no significant differences between the results obtained with the electrochemical and the reference method for the determination of NFV in tablets, with a confidence level of $95 \%$.

The analysis of NFV in urine samples from a healthy individual was made by adding the suitable quantity of the drug to the urine sample until the required concentration was obtained. Therefore, a volume of $500 \mu \mathrm{L}$ of a $5 \mathrm{mM}$ NFV stock solution was mixed with $25 \mathrm{~mL}$ of urine. This solution was dissolved to $50 \mathrm{~mL}$ with a solution containing $200 \mathrm{mM} \mathrm{KCl}$ and $100 \mathrm{mM}$ phosphate buffer $\mathrm{pH} 2$ to obtain the urine sample solution. Then, $5 \mathrm{~mL}$ of the urine solution were transferred to the electrochemical cell and aliquods of a NFV solution were again added. Results of the determination of NFV in urine sample are given in terms of recovery (Table 2 ). These assays were carried out at two levels, spiking NFV in urine with final concentrations of 40 and $50 \mu \mathrm{M}$, and performing three replicates for each level. The averages for the recovery were 100.3 and $101.5 \%$, respectively.

\section{Conclusions}

The use of an MWCNT-based sensor allows the voltammetric determination of NFV in different samples. The optimization of the main experimental variables was performed by means of a central composite design, which includes the study of interaction between variables. In this way, the obtained voltammetric signal was optimized to

Table 2. Recovery assay of NFV in urine samples.

\begin{tabular}{lllllll}
\hline $\mathrm{C}_{\mathrm{NFVr}}(\mu \mathrm{M})$ & $\mathrm{C}_{\mathrm{NFVo}}(\mu \mathrm{M})$ & Media $\mathrm{C}_{\mathrm{NFVo}}(\mu \mathrm{M})$ & $\mathrm{s}$ & Interval. & \% Recov. & Average recov. $(\%)$ \\
\hline 40 & 39.8 & 40.2 & 0.4 & {$[40.2 \pm 1.1]$} & 99.4 & 100.6 \\
& 40.6 & & & & 101.4 & \\
50 & 40.4 & 49.8 & 0.6 & {$[49.8 \pm 1.4]$} & 100.1 & 99.7 \\
& 50.0 & & & & 98.4 & \\
& 49.2 & & & & & \\
& 50.3 & & & & & \\
\hline
\end{tabular}

$[\mathrm{NFV}]_{\mathrm{r}}: \mathrm{NFV}$ real concentration; $[\mathrm{NFV}]_{\mathrm{o}}: \mathrm{NFV}$ obtained concentration 
obtain the highest response and the reproducibility of this sensor was estimated in $5.0 \%(\mathrm{RSD}, n=5)$.

A mechanism of oxidation of NFV was suggested based on the oxidation of the phenol group of the molecule, for which an electron and a proton are required.

According to the suggested method in this work, the sensor was applied to the NFV determination in pharmaceutical preparations and urine sample. No pretreatment was needed in the measure procedures.

\section{Acknowledgements}

Authors would like to acknowledge financial support from the Spanish Ministry of Science and Innovation (MICINN) and the European Regional Development Fund (FEDER) (TEC20013-40561-P), as well as through Junta de Castilla y León (BU212A12-2). L. Asturias-Arribas thanks the Spanish Ministry of Science, Culture and Sport for the FPU Research Fellowship (AP-2009-2648). M. R. Delfino is grateful to the BEC.AR Program of the Argentine Government for a grant received. Authors would like to thank Roche Ltd. for providing the Viracept ${ }^{\circledast}$ tablets.

\section{References}

[1] a) E. Wu, T. Sandobal, C. Lee, K. Zhang, B.-H. Liang, B. Shetty, in 7th North American ISSX Meeting., San Diego, CA, 1996, p. 326; b) J. H. Lillibridge, B. H. Liang, B. M. Kerr, S. Webber, B. Quart, B. V. Shetty, C. A. Lee, Drug Metab. Dispos. 1998, 26, 609-616.

[2] M. Tuseut Crest, J. M. Miró Meda, C. Codina Jané, N. Izco García, J. Ribas Sala, Farm. Hosp. 1999, 23, 79-93.

[3] a) A. Checa, R. Oliver, S. Hernández-Cassou, J. Saurina, Anal. Chim. Acta 2008, 616, 85-94; b) D. R. Weller, R. C. Brundage, H. H. Balfour Jr, H. E. Vezina, J. Chromatogr. B 2007, 848, 369-373; c) S. O. Choi, N. L. Rezk, A. D. M. Kashuba, J. Pharm. Biomed. Anal. 2007, 43, 1562-1567.

[4] R. Verbesselt, E. Van Wijngaerden, J. de Hoon, J. Chromatogr. B 2007, 845, 51-60.

[5] a) M. A. Marzinke, A. Breaud, T. L. Parsons, M. S. Cohen, E. Piwowar-Manning, S. H. Eshleman, W. Clarke, Clin. Chim. Acta 2014, 433, 157-168; b) A. D'Avolio, M. Simiele, M. Siccardi, L. Baietto, M. Sciandra, V. Oddone, F. R. Stefani, S. Agati, J. Cusato, S. Bonora, G. Di Perri, J. Pharm. Biomed. Anal. 2011, 54, 779-788; c) R. N. Tiwari, C. G. Bonde, J. Pharm. Biomed. Anal. 2011, 55, 435-445; d) L. Elens, S. Veriter, J. C. Yombi, V. Di Fazio, R. Vanbinst, D. Lison, P. Wallemacq, B. Vandercam, V. Haufroid, J. Chromatogr. B 2009, 877, 1805-1814; e) R. ter Heine, M. Davids, H. Rosing, E. C. M. van Gorp, J. W. Mulder, Y. T. van der Heide, J. H. Beijnen, A. D. R. Huitema, J. Chromatogr. B 2009, $877,575-580$.

[6] E. A. Pereira, G. A. Micke, M. F. M. Tavares, J. Chromatogr. A 2005, 1091, 169-176.

[7] P. Singh, R. Mehrotra, A. K. Bakhshi, J. Pharm. Biomed. Anal. 2010, 53, 287-294.

[8] N. Kaul, H. Agrawal, A. R. Paradkar, K. R. Mahadik, Anal. Chim. Acta 2004, 502, 31-38.
[9] M. A. Raviolo, I. C. Breva, J. Esteve-Romero, J. Chromatogr. A 2009, 1216, 3546-3552.

[10] K. Watanabe, E. Varesio, G. Hopfgartner, J. Chromatogr. B 2014, 965, 244-253.

[11] Y. Zhu, G.-m. Zeng, Y. Zhang, L. Tang, J. Chen, M. Cheng, L.-h. Zhang, L. He, Y. Guo, X.-x. He, M.-y. Lai, Y.-b. He, Analyst 2014, 139, 5014-5020.

[12] a) N. Erk, Anal. Lett. 2004, 37, 47-63; b) M. Gumustas, S. A. Ozkan, Anal. Bioanal. Chem. 2010, 397, 189-203; c) A. I. P. Cordoves, P. A. M. Farias, Curr. Pharm. Anal. 2011, 7, 71-78; d) A. A. Castro, A. I. P. Cordoves, P. A. M. Farias, Anal. Chem. Insights 2013, 8, 21-28.

[13] a) B. Molinero-Abad, M. A. Alonso-Lomillo, O. Domínguez-Renedo, M. J. Arcos-Martínez, Anal. Chim. Acta 2014, 812, 41-44; b) L. Asturias-Arribas, M. A. Alonso-Lomillo, O. Domínguez-Renedo, M. J. Arcos-Martínez, Anal. Chim. Acta 2014, 834, 30-36; c) A. Calvo-Pérez, O. Domínguez-Renedo, M. A. Alonso-Lomillo, M. J. Arcos-Martínez, Anal. Chim. Acta 2014, 833, 15-21.

[14] a) C. Herrero-Latorre, J. Álvarez-Méndez, J. BarcielaGarcía, S. García-Martín, R. M. Peña-Crecente, Anal. Chim. Acta 2015, 853, 77-94; b) C. Tang, U. Yogeswaran, S.-M. Chen, Anal. Chim. Acta 2009, 636, 19-27.

[15] O. Domínguez-Renedo, M. J. Arcos-Martínez, Anal. Chim. Acta 2007, 589, 255-260.

[16] a) M. A. Alonso-Lomillo, C. Yardimci, O. DomínguezRenedo, M. J. Arcos-Martínez, Anal. Chim. Acta 2009, 633, 51-56; b) L. del Torno-de Román, M. A. Alonso-Lomillo, O. Domínguez-Renedo, M. J. Arcos-Martínez, Sensor. Actuat. B-Chem. 2013, 176, 858-862; c) L. del Torno-de Román, M. A. Alonso-Lomillo, O. Domínguez-Renedo, C. Merino-Sánchez, M. P. Merino-Amayuelas, M. J. ArcosMartínez, Talanta 2011, 86, 324-328.

[17] STATGRAPHICS, Statistical Graphics Corp., Copy 19942001.

[18] a) G. E. P. Box, W. G. Hunter, J. S. Hunter, 1st ed., Reverté, Barcelona, 1999, p. 675; b) G. A. Lewis, D. Mathieu, R. T. L. Phan, Pharmaceutical Experimental Design, Dekker, New York, 1999; c) D. L. Massart, Elsevier, Amsterdam, 1988, p. 488.

[19] P. J. Rousseeuw, A. M. Leroy, Robust Regression and Outlier Detection Wiley, New York, 1989.

[20] a) J. Inczédy, T. Lengyel, A. M. Ure, A. Gelencsér, A. Hulanicki, Compendium of Analytical Nomenclature, 3rd ed., Port City Press Inc, Baltimore, 2000; b) ISO11843, Genève, Switzerland.

[21] a) E. S. Gil, R. O. Couto, Braz. J. Pharmacog. 2013, 23, $542-558$; b) T. A. Enache, A. M. Oliveira-Brett, J. Electroanal. Chem. 2011, 655, 9-16; c) M. Gattrell, D. W. Kirk, Can. J. Chem. Eng. 1990, 68, 997-1003.

[22] A. J. Bard, L. R. Faulkner, Electrochemical methods, fundamentals and applications, 2nd ed., Wiley, New York, 2001.

[23] R. E. Aarnoutse, C. P. W. G. M. Verweij-Van Wissen, W. J. M. Underberg, J. Kleinnijenhuis, Y. A. Hekster, D. M. Burger, J. Chromatogr. B Biomed. Sci. Appl. 2001, 764, $363-384$

[24] U.M. Compendium, (Ed.: U.S.P. Convention), 2011.

Received: February 7, 2016

Accepted: March 24, 2016

Published online: $\mathbf{\square} \mathbf{1 1}, 0000$ 


\section{FULL PAPERS}

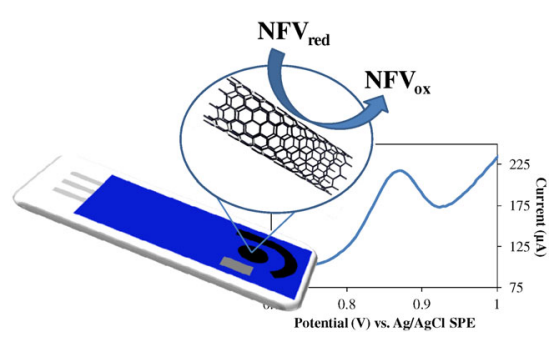

L. Asturias-Arribas,* M. R. Delfino, M. A. Alonso-Lomillo,

O. Domínguez-Renedo,

M. J. Arcos-Martínez

\section{$\square-\square \square$}

Electrochemical Oxidation of the Antiretroviral Drug Nelfinavir on Modified Screen-printed Electrodes 